\title{
Valores hematológicos de búfalos em diferentes faixas etárias criados na região central do Rio Grande do Sul
}

\section{Hematological parameters of buffaloes of different ages reared in the central region of Rio Grande do Sul}

\author{
Raqueli Teresinha França, ${ }^{*}$ Sonia Terezinha dos Anjos Lopes, ${ }^{*}$ Danieli Brolo Martins, ${ }^{*}$ Márcio Machado Costa, ${ }^{*}$ \\ Marta Lizandra do Rêgo Leal, ${ }^{* *}$ Cinthia Melazzo Andradre Mazzanti, ${ }^{*}$ Rodrigo Schuh, ${ }^{* * *}$ Guilherme Lopes Dornelles*
}

\begin{abstract}
Resumo
Este trabalho teve como objetivo avaliar os parâmetros hematológicos em búfalos de diferentes faixas etárias criados em sistema extensivo no Rio Grande do Sul. Utilizaram-se 45 búfalos, separados em três grupos: grupo 1 ( $n=12)$ animais com seis meses de idade; grupo $2(n=16)$ animais com 12 meses de idade e grupo $3(n=17)$ animais com 24 meses de idade. Verificou-se diferença significativa entre os grupos nos seguintes parâmetros hematológicos: contagem de hemácias, concentração de hemoglobina, hematócrito, volume corpuscular médio (VCM), leucócitos totais, neutrófilos segmentados, eosinófilos, monócitos e fibrinogênio. Os resultados encontrados indicam que existem variações no hemograma de bubalinos conforme a idade analisada. Dessa forma, é necessário que médicos-veterinários tenham conhecimento desses valores para que esses dados não sejam interpretados como indicativo de doença.
\end{abstract}

Palavras-chave: hematologia, búfalos, idade.

\begin{abstract}
This study aimed to evaluate the hematological parameters in buffaloes of different ages reared in extensive systems in Rio Grande do Sul. For this, 45 buffaloes were divided into three groups: group $1(n=12)$ six-months-old animals, group $2(n=16)$ twelve-months-old animals and group $3(n=17)$ twenty-four months-old animals. There were significant differences among groups in the following hematological parameters: red blood cells, hemoglobin, hematocrit, mean corpuscular volume (MCV), total leukocytes, segmented neutrophils, eosinophils, monocytes and fibrinogen. The results indicate that there are variations according to age. Thus, it is necessary that the veterinarians are aware of the influence of age in animals and the possible hematological values that can be found, for these data don't be interpreted as pathological changes.
\end{abstract}

Keywords: hematology, buffaloes, age.

\section{Introdução}

O búfalo (Bubalus bubalis) é um ruminante oriundo da Ásia que, na atualidade, está presente na Europa, Austrália, África e América. No Brasil, o rebanho oficial é de três milhões de búfalos, distribuídos em diversos estados brasileiros (Borghese, 2005). O produto de sua criação representa uma importante fonte de proteína de origem animal. Além disso, o bubalino é definido como um animal de múltiplo propósito, devido a sua capacidade de trabalho e de produzir carne e leite. Os búfalos possuem alta resistência a enfermidades, habilidade de sobreviver em climas com umidade alta, temperatura elevada e com fonte de alimento de baixa qualidade (Fernández et al., 2005; Ramírez-Iglesia et al., 2007).
Os resultados da hematologia representam o estado de saúde do animal e, como reflexo de um grupo, pode ser utilizada para avaliar o estado de saúde de um rebanho (Beechler et al., 2009). A análise sanguínea em ruminantes é uma importante extensão do exame físico, sendo sugestiva de certas condições de doença quando este apresenta incerteza para a conclusão do diagnóstico. Em muitos casos, pode também ser utilizada para o estabelecimento do prognóstico em algumas enfermidades (Jones, 2007). Sabese que diferenças hematológicas dentro dos intervalos de normalidade têm sido descritas em bovinos e bubalinos em relação ao sexo, idade, raça, período periparto, região onde vivem e alimentação (Silva, 1986; Ferrer et al., 2000; Birgel Junior et al., 2001; Fernández et al., 2005; Saut, 2006).

\footnotetext{
* Laboratório de Análises Clínicas Veterinárias (LACVET), Universidade Federal de Santa Maria. Avenida Roraima, no 1000 Cidade Universitária, prédio 97, Bairro Camobi - Santa Maria - RS 97105-900. A quem enviar correspondência: raquelifranca@yahoo.com.br

** Setor de Clínica de Grandes Animais, Universidade Federal de Santa Maria. Avenida Roraima, no 1000 Cidade Universitária, prédio 97, Bairro Camobi - Santa Maria - RS 97105-900.

*** Médico-veterinário autônomo.
} 
O fibrinogênio é uma proteína de fase aguda utilizada em ruminantes como uma ferramenta confiável para a avaliação da resposta do organismo frente a inflamações, infecções bacterianas e traumas cirúrgicos (Murata et al., 2004).

Considerando que a bubalinocultura é uma atividade em expansão, em especial na região sul do país (Damé, 2003), faz-se necessário o conhecimento sobre a hematologia de búfalos saudáveis de diferentes idades, para posterior comparação com possíveis processos patológicos e condições de estresse que estes animais possam passar durante sua vida. Como são escassos os estudos sobre a hematologia de búfalos criados em sistema extensivo na região central do Rio Grande do Sul, este trabalho tem como objetivo avaliar a influência da idade sobre parâmetros hematológicos em búfalos hígidos com seis, 12 e 24 meses de vida.

\section{Material e métodos}

Foram utilizados 45 búfalos mestiços, criados em sistema extensivo na região central do Rio Grande do Sul. Exames clínicos foram realizados previamente à coleta de sangue, a fim de constatar a higidez dos animais. Os bubalinos considerados hígidos foram divididos em três grupos de acordo com a idade, sendo: grupo 1 (G1) - animais com seis meses de idade ( $n=12)$; grupo 2 (G2) - animais com 12 meses de idade $(n=16)$ e grupo 3 (G3) animais com 24 meses de idade $(n=17)$.

Para realização do hemograma foram coletados de cada animal, $3 \mathrm{~mL}$ de sangue por punção da jugular, com tubo de coleta a vácuo, contendo anticoagulante etileno diamino tetracetato tripotássico (EDTA$\mathrm{K}_{3}$ ), a $10 \%$. As amostras foram armazenadas em caixa térmica e imediatamente transportadas ao Laboratório de Análises Clínicas Veterinárias da Universidade Federal de Santa Maria (LACVETUFSM), para realização das analises hematológicas.

As contagens de hemácias, leucócitos totais e a quantificação da hemoglobina foram realizadas em contador automático Mindray BC 2800 Vet®. A determinação do hematócrito foi obtida em centrífuga de micro-hematócrito, na rotação de 19720G. O volume corpuscular médio (VCM) e a concentração de hemoglobina corpuscular média (CHCM) foram determinados por cálculos indiretos. A contagem diferencial de leucócitos foi realizada em esfregaço sanguíneo corado com Panótico Rápido ${ }^{\circledR}$, utilizando microscopia de luz. O fibrinogênio foi determinado pelo método de precipitação pelo calor $\left(56^{\circ} \mathrm{C}\right.$ por 3 minutos), a leitura foi realizada através de um refratômetro.

Por apresentarem distribuição normal, mediante realização do teste de KolmogorovSmirnov, os dados foram submetidos à análise de variância (ANOVA), seguido de comparação de médias pelo teste de Tukey $(p<0,05)$.

\section{Resultados}

Os resultados de hematologia de búfalos mestiços de diferentes idades estão expressos nas Tabelas 1 e 2. Foram observados maiores valores $(p<0,01)$ para hemácias no grupo G1 em relação ao G2 e G3. Os valores da hemoglobina e do hematócrito foram mais elevados nos animais do G1 em relação aqueles dos grupos 2 e 3 . Menores valores do VCM foram obtidos nos animais dos grupos 1 e 2 em relação ao G3. Os valores de leucócitos totais foram mais elevados nos animais do G1 em relação aos do G2. O número de neutrófilos segmentados foi estatisticamente superior nos grupos G1 e G3 em relação aos valores encontrados no G2. Os eosinófilos nos animais pertencentes ao grupo G3 foram superiores aos valores observados no grupo G1. Os valores de monócitos foram superiores nos animais do grupo G1 em relação aos dos grupos G2 e G3. O fibrinogênio foi mais elevado nos animais do G3 em relação ao G1 e G2. Nos demais parâmetros analisados não houve diferença de valores entre grupos.

Tabela 1: Eritrograma de búfalos mestiços, de diferentes idades criados no Rio Grande do Sul (G1: animais com seis meses de idade; G2: animais com um ano de idade e G3: animais com dois anos de idade).

\begin{tabular}{l|c|c|c}
\hline \multirow{2}{*}{ Variável } & $\begin{array}{c}\text { G1 ( } \mathbf{n - 1 2 )} \\
\mathbf{6} \text { meses }\end{array}$ & $\begin{array}{c}\text { G2 } \mathbf{( n - 1 6 )} \\
\mathbf{1 2} \text { meses }\end{array}$ & $\begin{array}{c}\text { G3 } \mathbf{( n - 1 7 )} \\
\mathbf{2 4} \text { meses }\end{array}$ \\
\cline { 2 - 4 } & Média/DP & Média/DP & Média/DP \\
\hline Hemácias $\left(\times 10^{6}\right)$ & $7,96 \pm 0,62^{\mathrm{a}}$ & $6,02 \pm 0,50^{\mathrm{b}}$ & $6,36 \pm 0,45^{\mathrm{b}}$ \\
Hemoglobina $(\mathrm{g} / \mathrm{dL})$ & $14,4 \pm 0,80^{\mathrm{a}}$ & $10,67 \pm 0,78^{\mathrm{b}}$ & $12,27 \pm 0,94^{\mathrm{c}}$ \\
Hematócrito $(\%)$ & $41,33 \pm 2,17^{\mathrm{a}}$ & $31,50 \pm 1,86^{\mathrm{b}}$ & $36,70 \pm 3,29^{\mathrm{c}}$ \\
VCM (fl) & $52,13 \pm 3,50^{\mathrm{a}}$ & $52,51 \pm 3,74^{\mathrm{a}}$ & $57,88 \pm 5,24^{\mathrm{b}}$ \\
CHCM (\%) & $34,87 \pm 1,76^{\mathrm{a}}$ & $33,89 \pm 2,20^{\mathrm{a}}$ & $33,57 \pm 2,88^{\mathrm{a}}$ \\
Fibrinogênio (mg/dL) & $440 \pm 126,49^{\mathrm{a}}$ & $493,33 \pm 127,99^{\mathrm{a}}$ & $625 \pm 100^{\mathrm{b}}$ \\
\hline
\end{tabular}

Média seguida por letras diferentes na mesma linha diferem estatisticamente entre si a $1 \%$ de probabilidade pelo teste de TUKEY. DP= Desvio-padrão, $\mathrm{VCM}=$ Volume corpuscular médio, $\mathrm{CHCM}=$ Concentração de hemoglobina corpuscular média.

Tabela 2: Valores absolutos do leucograma de búfalos mestiços, de diferentes idades criados no Rio Grande do Sul, (G1: animais com seis meses de idade; G2: animais com um ano de idade e G3: animais com dois anos de idade).

\begin{tabular}{l|c|c|c}
\hline \multirow{2}{*}{ Variável } & $\begin{array}{c}\text { G1(n-12) } \\
\mathbf{6} \text { meses }\end{array}$ & $\begin{array}{c}\text { G2 (n-16) } \\
\mathbf{1 2} \text { meses }\end{array}$ & $\begin{array}{c}\text { G3 }(\mathbf{n}-\mathbf{1 7}) \\
\mathbf{2 4} \text { meses }\end{array}$ \\
\cline { 2 - 4 } & Média/DP & Média/DP & Média/DP \\
\hline Leucócitos & $15.600 \pm 3736,27^{\mathrm{a}}$ & $11.900 \pm 1962,05^{\mathrm{b}}$ & $14.100 \pm 1765,02^{\mathrm{ab}}$ \\
Bastonetes $(\mu \mathrm{L})$ & $0 \pm 0^{\mathrm{a}}$ & $15,50 \pm 42,76^{\mathrm{a}}$ & $8,17 \pm 33,71^{\mathrm{a}}$ \\
Segmentados $(\mu \mathrm{L})$ & $4.574 \pm 1.322,04^{\mathrm{a}}$ & $2.519 \pm 1.118,15^{\mathrm{b}}$ & $3.921 \pm 819,34^{\mathrm{a}}$ \\
Linfócitos $(\mu \mathrm{L})$ & $10.407 \pm 3.100,88^{\mathrm{a}}$ & $8.765 \pm 1.513,12^{\mathrm{a}}$ & $9.430 \pm 1.624,21^{\mathrm{a}}$ \\
Eosinófilos $(\mu \mathrm{L})$ & $186 \pm 221,12^{\mathrm{a}}$ & $404 \pm 489,34^{\mathrm{ab}}$ & $577 \pm 391,32^{\mathrm{b}}$ \\
Basófilos $(\mu \mathrm{L})$ & $67 \pm 122,02^{\mathrm{a}}$ & $25 \pm 74,30^{\mathrm{a}}$ & $46 \pm 64,82^{\mathrm{a}}$ \\
Monócitos $(\mu \mathrm{L})$ & $381 \pm 317,21^{\mathrm{a}}$ & $150 \pm 145,76^{\mathrm{b}}$ & $163 \pm 102,22^{\mathrm{b}}$ \\
\hline
\end{tabular}

Média seguida por letras diferentes na mesma linha diferem estatisticamente entre si a $5 \%$ de probabilidade pelo teste de TUKEY. DP=Desvio-padrão 


\section{Discussão}

Para considerar resultados de exames laboratoriais como anormais, deve-se ter conhecimento da faixa de variação dos parâmetros em uma população de animais saudáveis. Esses valores devem ser estabelecidos para cada espécie (Lassen, 2007). Em estudo realizado por Ferrer et al. (2000), foi demonstrado não haver influência da raça sobre os parâmetros hematológicos de búfalos. Fato relevante, pois neste estudo utilizaram-se animais mestiços, podendo estes resultados ser utilizados para animais de raças puras.

Nos animais do presente estudo, observaram-se menores valores no número de hemácias nos grupos com um e dois anos de idade (Tabela 1). Este resultado corrobora com estudos realizados por Ciaramella et al. (2005) e Gomes et al. (2010), que utilizando búfalos de diferentes idades, constataram que os animais mais jovens possuíam maior número de hemácias e de hematócrito quando comparados aos mais velhos, devido à diminuição da atividade hematopoiética medular e da produção de hormônios da tireoide com o avançar da idade.

O teor de hemoglobina obtido nos búfalos dessa pesquisa diminuiu nos animais do G2 quando comparados com os animais do G1 (Tabela 1), ocorrendo novamente elevação no G3. Ferrer et al. (2000) citaram que há variação na concentração de hemoglobina de bubalinos de acordo com o estado físiológico, raça, idade, exercício, temperatura, clima e manejo. Em um estudo realizado com búfalas mestiças de diferentes idades, foi observado que os valores de hemoglobina foram menores em animais de três e quatro anos quando comparados com fêmeas de cinco e seis anos (Fernández et al., 2005). Já em estudo realizado por Gomes et al. (2010), que avaliaram búfalos de diferentes faixas etárias, observaram diminuição na concentração de hemoglobina com o avanço da idade. A variação encontrada na concentração de hemoglobina não alterou o $\mathrm{CHCM}$ dos animais deste estudo. Quanto ao VCM, observaram-se menores valores nos animais com seis e 12 meses de vida (Tabela 1). Jain (1993) cita que no terceiro e quarto mês de vida ocorre diminuição do VCM devido à substituição das hemácias fetais. Posteriormente, ocorre aumento gradual no VCM acompanhado por redução no número de hemácias.

Em relação aos leucócitos totais, pode-se observar que os bubalinos do G1 apresentaram valores superiores aos do G2 (Tabela 2). Este trabalho corrobora com o estudo realizado por Ramírez-Iglesia et al. (1999), que utilizaram búfalos com idade superior e inferior a nove meses e observaram que os animais mais jovens tinham maior número de leucócitos em relação aos animais com um ano de idade. Tais resul- tados podem estar relacionados com um aumento gradativo no número de leucócitos após o nascimento, conforme citado por Jain (1993).

O número de eosinófilos altera-se com o avanço da idade, sendo que animais com seis meses apresentam valores mais baixos em relação aos animais adultos. $O$ aumento dos eosinófilos com a idade deve-se à maior exposição dos animais ao parasitismo (Jain, 1993). Neste estudo, observouse aumento gradativo no número de eosinófilos entre os grupos (Tabela 2). Os animais do G1 estão em período de transição imunológica e iniciando o pastoreio, bem como o contato aos parasitos presentes no ambiente. Assim, o tempo de exposição aos antígenos parasitários é mais prolongado nos animais do G3 em relação aos demais grupos.

O número de monócitos parece não sofrer influência com o avanço da idade (Jain, 1993). No entanto, nos animais deste estudo ocorreu diminuição gradual no número de monócitos (Tabela 2) nos três grupos, ocorrendo diferença estatística entre os animais do G1 em relação aos do G3.

Em ruminantes adultos há predomínio de linfócitos. Entretanto, em recém-nascidos, o número de neutrófilo é superior aos linfócitos, ocorrendo reversão desta relação nas primeiras semanas de vida (Jain, 1993). Neste estudo, ocorreu um predomínio constante de linfócitos, não havendo diferença estatística entre os grupos. No entanto, foi observada diferença significativa nos neutrófilos do G2, que apresentou diminuição em seu número comparado ao G1 e G3. Mesmo com essa diminuição nos neutrófilos do $\mathrm{G} 2$, a relação entre neutrófilo e linfócito permanece dentro dos valores normais descritos por Morris (2006), demonstrando que não há inversão dessa relação conforme a idade dos animais.

No G3 pode-se observar um aumento no fibrinogênio em relação aos demais grupos estudados. Tal fato pode estar diretamente relacionado com a maior idade destes animais, visto que em humanos com idade mais avançada também há um aumento fisiológico do fibrinogênio (Hager et al., 1994). Além disso, vacinas e seus adjuvantes também podem induzir a um aumento desta proteína (Jain, 1993; Mills et al., 1998; Ciarlini et al., 2005), já que este estes animais foram mais frequentemente expostos a este processo quando comparado aos animais mais jovens.

\section{Conclusão}

Com os resultados obtidos e nas condições em que foi realizado este experimento, pode-se concluir que existe influência da faixa etária sobre parâmetros hematológicos de búfalos, tornando-se fundamental o conhecimento dessas modificações, para correta interpretação do hemograma.

\section{Agradecimentos}

Ao médico-veterinário Marcelo Fortes, proprietário da Fazenda do Cedro, por ceder os animais para este estudo.

\section{Referências}

BEECHLER, B.R.; JOLLES, A. E.; EZENWA, V.O. Evaluation of Hematologic Values in Free-ranging African Buffalo (Syncerus Caffer). Journal of Wildlife Diseases, v. 45, p. 57-66, 2009.
BIRGEL JUNIOR, E. H.; D’ANGELINO, J. L.; BENESI, F. J.; BIRGEL, E. H. Valores de referência do leucograma de bovinos da raça Jersey criados no Estado de São Paulo. Brazilian Journal of Veterinary Research and Animal Science. v. 38, p. 136-141, 2001. 
BORGHESE, A.; MAZZI, M. Buffalo Population and Strategies in the World. In: BORGHESE, A. Buffalo Production and Research. Rome, 2005, p. 1-40.

CIARAMELLA, P. et al. Haematological proûle on non-lactating mediterranean bufaloes (Bubalus Bubalis) ranging in age from 24 months to 14 years. Research in Veterinary Science, v. 79, p. 77-80, 2005.

CIARLINI, P. C.; ANTONIO, D. B. A.; BARBIERE, F.; BONELLO, F. L.; FEITOSA, F. L. F. Efeito da vacina contra rucelose bovina sobre a capacidade neutrofílica de redução do NBT. Ars Veterinária, v. 21, p. 251-256, 2005.

DAMÉ, M. C. F.; SILVA, W. P. Observações preliminares sobre a Produção de Leite Bubalino no Rio Grande do Sul. Pelotas: Embrapa Clima Temperado, 2003,18 p. Disponível em: http://www.cpact. embrapa.br/publicacoes/download/documentos/documento_111.pdf. Acesso em: janeiro, 2010.

FERNÁNDEZ, A. H.; ROMERO, O.; MONTIEL, N.; TRUJILLO, H. N.; CAHUAO, N. Determinación de valores de referencia hematológicos en búfalas (Bubalus bubalis) preparto y postparto en una unidad de producción en el sur del lago de Maracaíbo, Venezuela. Revista Cientifica FCV-LUZ, v. 15, p.119-124, 2005.

FERRER, J. M.; ÁRRAGA, C. M.; BARBOZA, M. Caracterización hematológica de La especie Bubalus bubalis por sexo y edad. Revista Cientifica FCV-LUZ,v.10, p. 508- 514, 2000.

GOMES, V.; MOURA, J. A.; MADUREIRA, K. M.; BAPTISTELLA, F.; KITAMURA S. S.; BLAGITZ, M. G.; BENESI, F. J. Valores de referência e influência da idade no eritrograma de bubalinos da raça Murrah. Pesquisa Veterinária Brasileira, v. 30, p. 301-304, 2010.

HAGER, K.; SEEFRIED, G.; FELICETTI, M.; PLATT, D. Plasma fibrinogen - are there age-dependent changes?. Archives of Gerontology and Geriatrics, v. 19, p. 99-106, 1994.

JAIN N.C. Essential veterinary hematology. Philadelphia: Lea and Febiger, 1993. $417 p$.
JONES, M.L; ALLISON, R.W. Evaluation of the ruminant complete blood cell count. Veterinary Clinics, v. 23, p. 377-402, 2007.

LASSEN, E.D. Considerações sobre interpretação de resultados de exames laboratoriais. In: THRALL, M.A. Hematologia e Bioquímica Clínica Veterinária. São Paulo: Roca, 2007, Cap. 3, p.43-50.

MILLS, P.C.; AUER, D.E.; KRAMER, H.; BARRY, D.; NG, J.C. Effects of inflammation-associated acute-phase response on hepatic and renal indices in the horse. Australian Veterinary Journal, v. 76, p.187194,1998.

MORRIS, D. D. Alterações no leucograma. In: SMITH, B.P. Tratado de medicina Interna de Grandes Animais. São Paulo: Manole, 2006, Cap. 25, p. 420-426.

MURATA, H.; SHIMADA N.; YOSHIOKA, M. Current research on acute phase proteins in veterinary diagnosis: an overview. The Veterinary Journal, v.168, p. 28-40, 2004.

RAMÍREZ-IGLESIA, L. N.; AZUAJE, K. K.; SÁNCHEZ, F.; RAMÍREZ, A. D. Observaciones hematológicas en búfalos de agua (Bubalus Bubalis) aparentemente sanos en el occidente de Venezuela. Revista Científica, FCV LUZ, v. 9, p. 524-531, 1991.

RAMíREZ-IGLESIA, L. N.; ARAUJO, G.; RAMÍREZ, D. A. Hematología em Búfalas Lecheras Mestizas (Bubalus Bubalis) y sus crías en un rebaño ubicado en una zona de bosque seco tropical. Mundo Pecuario, v. 3, p. 90-95, 2007.

SILVA, M.B. 1986. Contribuição ao quadro eritrocitário de bubalinos fêmeas das raças Jafarabadi, Murrah e Mediterrânea criados no estado de São Paulo. Dissertação de Mestrado em Clínica Médica, Universidade de São Paulo, São Paulo. 115 p.

SAUT, J. P. E. ; JUNIOR BIRGEL, E. H. Influência do período pós-parto sobre o leucograma de fêmeas bovinas da raça holandesa. Brazilian Journal of Veterinary Research and Animal Science, v. 43, p. 588 597, 2006. 